\title{
Spontaneous Rupture of Renal Cell Carcinoma in a Horseshoe Kidney: A Case Report
}

\author{
Tasuku Hiroshige ${ }^{a}, \mathrm{c}$, Yoshiro Eguchi ${ }^{\mathrm{a}}$, Kazuhisa Ejima ${ }^{\mathrm{a}}$, \\ Osamu Yoshizumi ${ }^{a}$, Tsukasa Igawa ${ }^{b}$
}

\begin{abstract}
Spontaneous rupture of renal cell carcinoma (RCC) in a horseshoe kidney has not been described previously. We report a case of this condition in a 52-year-old man with a chief complaint of back pain. Spontaneous rupture of renal tumor in a horseshoe kidney was diagnosed by enhanced computed tomography, and treated with transarterial embolization (TAE). Radical heminephrectomy was performed after TAE. This case indicates that enhanced computed tomography and renal angiography are desirable prior to surgery for evaluation of the anatomical variations of a horseshoe kidney, and that preoperative TAE may be beneficial for achieving reliable vascular control.
\end{abstract}

Keywords: Rupture; Renal cell carcinoma; Horseshoe kidney

\section{Introduction}

Horseshoe kidney is the most common renal fusion anomaly and forms between the fourth and sixth weeks of fetal life [1]. Patients are often asymptomatic and the anomaly is discovered during imaging studies performed for other reasons. Renal cell carcinoma (RCC) in a horseshoe kidney is relatively rare. Spontaneous rupture of RCC is also rare and generally presents with venous bleeding. Arterial hemorrhage is uncommon in these cases. Spontaneous rupture of RCC in a horseshoe kidney has not been described previously. Here, we present a case in which enhanced computed tomography (CT), angiography and arteriography with transarterial embolization (TAE) were beneficial for treatment of spontaneous rupture of $\mathrm{RCC}$ in a horseshoe kidney.

Manuscript accepted for publication June 22, 2015

aDepartment of Urology, St. Maria Hospital, Kurume, Fukuoka 830-0042, Japan

${ }^{b}$ Department of Urology, Kurume University School of Medicine, Kurume, Fukuoka 830-0011, Japan

${ }^{\mathrm{c} C}$ Corresponding Author: Tasuku Hiroshige, Department of Urology, St. Maria Hospital, Kurume, Kurume, 422 Tsubukuhonmachi, Kurume, Fukuoka 8300042, Japan. Email: tkkn19841220@yahoo.co.jp

doi: http://dx.doi.org/10.14740/wjnu215w

\section{Case Report}

A 52-year-old man came to the emergency department of our hospital with sudden onset of chest and back pain. He had a history of hypertension that was controlled by oral medication. His vital signs were not particularly notable and laboratory tests revealed slight anemia and an inflammatory status. Results from electrocardiography and ultrasonic cardiography were not consistent with coronary heart disease. Emergency enhanced CT showed a horseshoe kidney and a hypervascular solid mass (50 $\times 50 \mathrm{~mm}$ ) that was suspected to be due to RCC at the lower pole of the left side. Enhanced CT also showed a large hematoma in the left retroperitoneal space with extravasation of the contrast agent, which suggested arterial bleeding, and four renal arteries branching off from the aorta and feeding the left side of the kidney (Fig. 1). Digital subtraction angiography (DSA) carried out via a transfemoral approach with selective catheterization of renal arteries revealed active bleeding from a branch from one of the four renal arteries feeding the renal tumor.

Based on these findings, the case was diagnosed as spontaneous rupture of renal tumor in a horseshoe kidney. Superselective catheterization of the bleeding vessel was performed using a 2.1 Fr microcatheter (Sniper 2 Selective; Terumo, Tokyo, Japan) with a hydrophilic 0.016-inch guidewire (Radifocus; Terumo). Transarterial embolization was performed successfully using two 3 to $2 \mathrm{~mm}$ and three 6 to $2 \mathrm{~mm}$ and 5 to $2 \mathrm{~mm}$ 0.018-inch-diameter Tornado microcoils (Cook Inc., Bloomington, IN) and gelatin sponge (Fig. 2).

Follow-up CT at 27 days after TAE showed that the leftsided perirenal hematoma had not increased in size. Radical heminephrectomy was performed 37 days after TAE. The procedure was completed in $301 \mathrm{~min}$ with an estimated blood loss of 1,506 mL. The patient required a total of two units of packed red blood cells throughout the operation. Gross examination of the removed kidney revealed a white and yellow solid tumor of $6 \mathrm{~cm}$ in diameter located at the lower pole and involving perinephric tissues (Fig. 3). Microscopic examination revealed atypical epithelial cells with clear eosinophilic cytoplasm proliferating in an alveolar or sheet pattern, accompanied by a wide range of necrosis and bleeding. These findings led to a diagnosis of clear cell RCC. The staging was pT3aN0M0, clear cell RCC, G2. The patient was discharged on postoperative day 9 with no complications and remains in complete remission after 6 months of follow-up. 

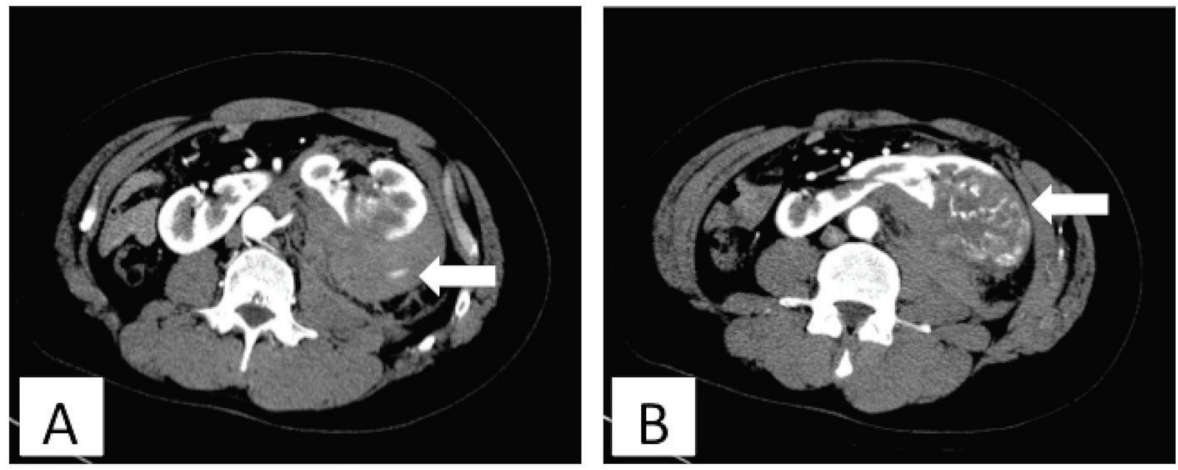

Figure 1. Enhanced computed tomography in the first examination showed left retroperitoneal hematoma $(A)$ and a horseshoe kidney and a hypervascular solid mass (B). The white arrows indicate extravasation of contrast agent (A) and a renal tumor (B).
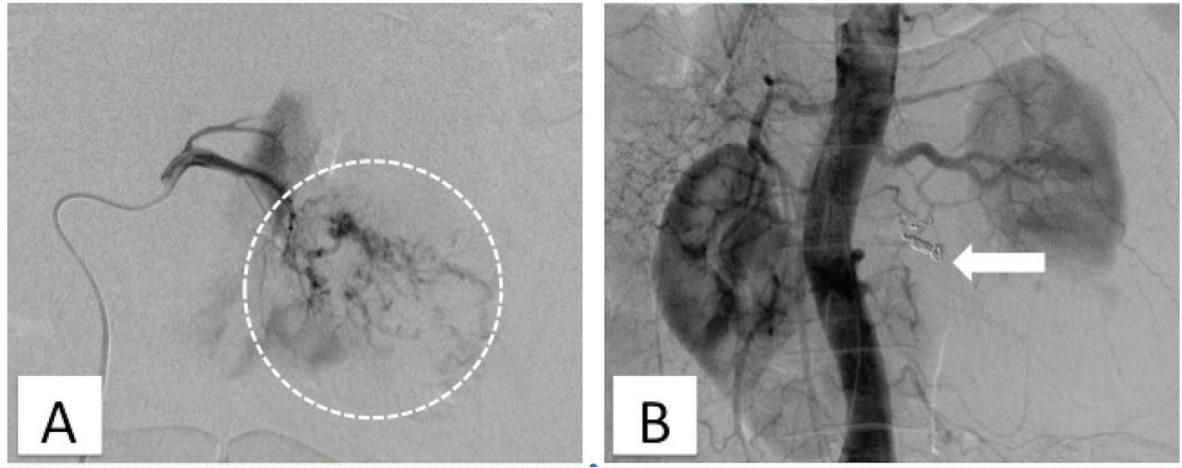

Figure 2. Digital subtraction angiography with selective catheterization of renal arteries shows active bleeding from a branch from renal arteries (A). The white circle in a broken line indicates an avascular area and pooling of contrast agent. Aortography after TAE showed disappearance of extravasation of contrast agent (B). The white arrow indicates the embolized portion.

\section{Discussion}

The anomaly of horseshoe kidney consists of two distinct re-

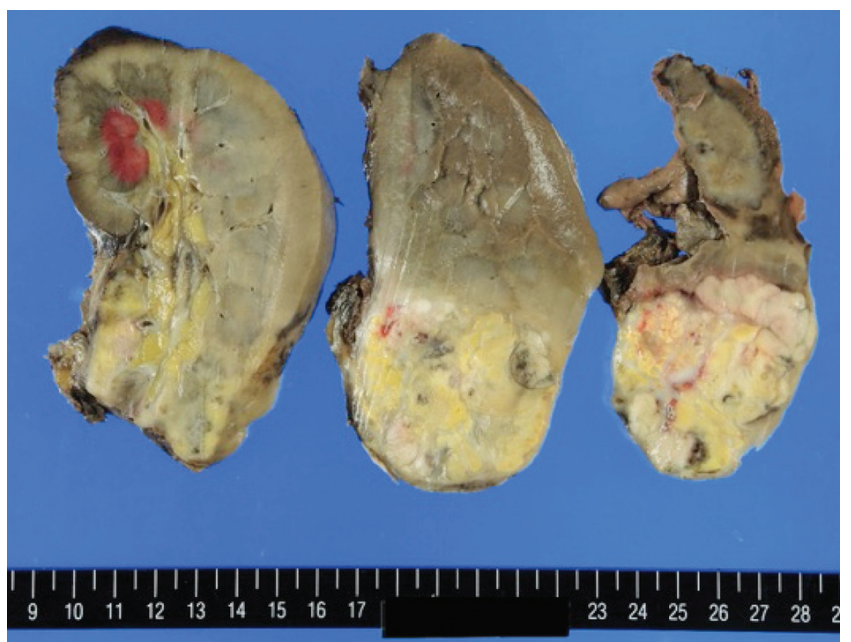

Figure 3. The gross appearance of the removed kidney revealed a white and yellow solid tumor of $6 \mathrm{~cm}$ in diameter located at the lower pole. nal masses lying vertically on either side of the midline and connected at their respective lower poles by a parenchymatous or fibrous isthmus that crosses the midplane of the body in the prenatal period. Horseshoe kidney occurs in $0.25 \%$ of the population, or about 1 in 400 persons, and is more common in males, with a ratio slightly greater than $2: 1$ [1]. Renal pelvic tumor develops 3 - 4 times more frequently in a horseshoe kidney. The factors predisposing to tumor formation result from the presence of the defect and include urinary obstruction, susceptibility to nephrolithiasis, and chronic infection [2]. The incidence of Wilms tumor in horseshoe kidneys is also higher than that in the general population due to abnormal metanephric mesenchyme proliferation [3]. However, the incidence of $\mathrm{RCC}$ is no greater than that in the general population.

The blood supply to a horseshoe kidney can be variable. Kolln et al classified horseshoe kidneys into three types in which each renal artery branches from the aorta; several renal arteries branch from the aorta to supply blood to the isthmus and both kidneys; and renal arteries branches from the inferior mesenteric, common or external iliac or sacral arteries to supply to the isthmus [4]. In our case, four renal arteries branched off from the aorta and fed the left side of the kidney. Enhanced CT or angiography is useful for understanding the anatomy of the aberrant arteries.

Spontaneous rupture of RCC has been reported in $0.3-$ 
Table 1. Literature Review of Preoperative Transarterial Embolization for Malignancy in Horseshoe Kidneys

\begin{tabular}{|c|c|c|c|c|c|c|}
\hline & $\begin{array}{l}\text { Age (years)/ } \\
\text { gender }\end{array}$ & Tumor location & $\begin{array}{l}\text { Aberrant vessel } \\
\text { supply }\end{array}$ & Embolic material & Operative method & Histology \\
\hline Fazio et al [11] & $72 / \mathrm{F}$ & Isthmus & $\begin{array}{l}\text { One vessel from } \\
\text { the aorta }\end{array}$ & Unknown & Isthmectomy & $\begin{array}{l}\text { Renal cell } \\
\text { carcinoma }\end{array}$ \\
\hline $\operatorname{Kim}[12]$ & $59 / \mathrm{M}$ & Left kidney & $\begin{array}{l}\text { Two vessels from } \\
\text { the aorta and one } \\
\text { vessel from the left } \\
\text { common iliac artery }\end{array}$ & Microcoils & Tumor enucleation & $\begin{array}{l}\text { Renal cell } \\
\text { carcinoma }\end{array}$ \\
\hline $\begin{array}{l}\text { Wilhelmsen } \\
\text { et al [14] }\end{array}$ & $47 / \mathrm{M}$ & Left ureter & $\begin{array}{l}\text { Three vessels from the } \\
\text { aorta and two vessels } \\
\text { from the bilateral } \\
\text { common iliac artery }\end{array}$ & $\begin{array}{l}\text { Microspheres } \\
\text { (Embozene), } \\
\text { microcoils }\end{array}$ & Heminephroureterectomy & $\begin{array}{l}\text { Urothelial } \\
\text { carcinoma }\end{array}$ \\
\hline
\end{tabular}

$0.6 \%$ of cases of RCC based on various definitions $[5,6]$. The most common causes of rupture responsible for perirenal hemorrhage in the general population are ruptured angiomyolipomas (33\%), followed by RCCs (26\%), vascular diseases (26\%), renal vessel anomaly (18\%), and infection (10\%) [7]. Regarding the mechanisms of RCC rupture, several theories have been proposed, including congestion of renal veins due to obstruction by the RCC, vascular extension and tearing by rapid enlargement of the $\mathrm{RCC}$, and direct invasion of the RCC into the renal vasculature [8]. Enhanced CT is most effective for detection of spontaneous rupture of RCC, but the detection rate of the tumor is only about $60 \%$ and it is more difficult to identify the tumor at the acute stage of the rupture [9]. Angiography in a case of RCC shows an avascular area, pooling of contrast agent, and an arteriovenous fistula, but it is also difficult to identify the tumor due to compression by hematoma in a case of tumor rupture. However, enhanced CT and angiography in our case showed extravasation of contrast agent and both showed a hypervascular tumor that was suspected to be RCC.

In general, angiomyolipomas larger than $4 \mathrm{~cm}$ have an increased risk of rupture [10]. However, it is unclear if spontaneous rupture of RCC is correlated with the size of the tumor, and spontaneous rupture of RCC less than $1 \mathrm{~cm}$ has been reported [5]. Most cases of spontaneous rupture of RCC are treated with radical nephrectomy [8]. Some cases have been treated at regular intervals, but the appropriate time until performance of radical nephrectomy is unclear. In our case, we waited 37 days to perform radical nephrectomy and adhesion around the kidney at the time of the operation was very firm. Therefore, it may be better to perform this surgery at an earlier time.

In our case, enhanced $\mathrm{CT}$ and renal angiography revealed the tumor location, and extravasation of the contrast agent indicated suspected active bleeding. The mechanism of development of arterial bleeding was unclear, but these findings per- mitted diagnosis of spontaneous rupture of renal tumor in a horseshoe kidney. In radical heminephrectomy performed 37 days after TAE, it was possible to resect the tumor completely due to the clear understanding of the vascular supply provided by enhanced CT and renal angiography, even though the tumor had ruptured. In addition, it was also possible by a block in the blood flow through the RCC due to TAE.

The present case is an extremely rare example of spontaneous rupture of RCC complicated by horseshoe kidney. To our knowledge, five cases of malignant tumor in a horseshoe kidney that was treated with preoperative TAE have been reported (Table 1) [11-14]. However spontaneous rupture of RCC in a horseshoe kidney that treated with TAE has not been reported previously.

The vascular supply to horseshoe kidneys can vary and the collateral circulation of tumor nutrient vessels in RCC is likely to be complicated. Thus, enhanced CT and renal angiography are important for understanding the vascular supply, while preoperative TAE for RCC in a horseshoe kidney may facilitate subsequent surgical resection.

\section{Conflict of Interest}

The authors state that they have no conflict of interest to declare.

\section{References}

1. Bauer SB. Anomalies of the upper urinary tract. In: Wein AJ, Kavoussi LR, Novick AC, Partin AW, Peters CA, eds. Campbell's Urology. Saunders, Philadelphia. 2007; pp. 3269-3334.

2. Buntley D. Malignancy associated with horseshoe kid- 
ney. Urology. 1976;8(2):146-148.

3. Neville H, Ritchey ML, Shamberger RC, Haase G, Perlman S, Yoshioka T. The occurrence of Wilms tumor in horseshoe kidneys: a report from the National Wilms Tumor Study Group (NWTSG). J Pediatr Surg. 2002;37(8):1134-1137.

4. Kolln CP, Boatman DL, Schmidt JD, Flocks RH. Horseshoe kidney: a review of 105 patients. J Urol. 1972;107(2):203-204.

5. Skinner DG, Colvin RB, Vermillion CD, Pfister RC, Leadbetter WF. Diagnosis and management of renal cell carcinoma. A clinical and pathologic study of 309 cases. Cancer. 1971;28(5):1165-1177.

6. Patel NP, Lavengood RW. Renal cell carcinoma: natural history and results of treatment. J Urol. 1978;119(6):722726.

7. McDougal WS, Kursh ED, Persky L. Spontaneous rupture of the kidney with perirenal hematoma. J Urol. 1975;114(2):181-184.

8. Yamada S, Yotsueda H, Nagara T, Goto K, Nakashima Y, Hirakata H, Fujimi S, et al. Heterochronic spontaneous rupture of bilateral renal cell carcinomas in a hemodialysis patient. Intern Med. 2013;52(6):667-671.
9. Belville JS, Morgentaler A, Loughlin KR, Tumeh SS. Spontaneous perinephric and subcapsular renal hemorrhage: evaluation with CT, US, and angiography. Radiology. 1989;172(3):733-738.

10. Steiner MS, Goldman SM, Fishman EK, Marshall FF. The natural history of renal angiomyolipoma. J Urol. 1993;150(6):1782-1786.

11. Fazio L, Razvi H, Chin JL. Malignancy in horseshoe kidneys: review and discussion of surgical implications. Can J Urol. 2003;10(3):1899-1904.

12. Kim TH. Renal cell carcinoma in a horseshoe kidney and preoperative superselective renal artery embolization: a case report. Korean J Radiol. 2005;6(3):200-203.

13. Palmowski M, Kiessling F, Lopez-Benitez R, Kauffmann GW, Hallscheidt P. Preoperative embolization of a tumorbearing horseshoe kidney via both channels of a concomitant aortic dissection. Cardiovasc Intervent Radiol. 2007;30(3):501-503.

14. Wilhelmsen S, Janitzky A, Porsch M, Liehr UB, Dudeck $\mathrm{O}$. Value of preoperative superselective embolization of the isthmus in a patient with upper urinary tract urothelial carcinoma and horseshoe kidney. Cardiovasc Intervent Radiol. 2011;34(Suppl 2):S98-101. 